University of Wollongong

Research Online

Faculty of Engineering and Information

Faculty of Engineering and Information

Sciences - Papers: Part B

Sciences

2019

Degradation of diclofenac, trimethoprim, carbamazepine, and sulfamethoxazole by laccase from Trametes versicolor: Transformation products and toxicity of treated effluent

\author{
Sultan Alharbi \\ Taibah University, University of Wollongong, skma437@uowmail.edu.au \\ Long D. Nghiem \\ University of Technology Sydney, University of Wollongong, longn@uow.edu.au \\ Jason P. Van De Merwe \\ Griffith University \\ Frederic Leusch \\ Griffith University \\ Muhammad Bilal Asif \\ University of Wollongong, mba409@uowmail.edu.au
}

See next page for additional authors

Follow this and additional works at: https://ro.uow.edu.au/eispapers1

Part of the Engineering Commons, and the Science and Technology Studies Commons

Research Online is the open access institutional repository for the University of Wollongong. For further information contact the UOW Library: research-pubs@uow.edu.au 


\title{
Degradation of diclofenac, trimethoprim, carbamazepine, and sulfamethoxazole by laccase from Trametes versicolor: Transformation products and toxicity of treated effluent
}

\author{
Abstract \\ The degradation of diclofenac (DCF), trimethoprim (TMP), carbamazepine (CBZ), and sulfamethoxazole \\ (SMX) by laccase from Trametes versicolor was investigated. Experiments were conducted using the \\ pharmaceuticals individually, or as a mixture at different initial concentrations ( 1.25 and $5 \mathrm{mg} / \mathrm{L} \mathrm{each}$ ). \\ The initial enzymatic activity of all the treated samples was around 430-460 U (DMP) /L. The removal of \\ the four selected pharmaceuticals tested individually was more effective than when tested in mixtures \\ under the same conditions. For example, $5 \mathrm{mg} \mathrm{DCF} / \mathrm{L}$ was completely removed to below its detection \\ limit $(1 \mu \mathrm{g} / \mathrm{L})$ within $8 \mathrm{~h}$ in the individual experiment vs. after $24 \mathrm{~h}$ when dosed as a mixture with the other \\ pharmaceuticals. A similar trend was visible with other three pharmaceuticals, with 95 vs. $39 \%$, 82 vs. \\ $34 \%$ and 56 vs. $49 \%$ removal after $48 \mathrm{~h}$ with $5 \mathrm{mg} / \mathrm{L}$ of TMP, CBZ, and SMX tested individually or as \\ mixtures, respectively. In addition, at the lower initial concentration $(1.25 \mathrm{mg} / \mathrm{L}$ each), the removal \\ efficiency of TMP, CBZ, and SMX in mixtures was lower than that obtained at the higher initial \\ concentrations ( $5 \mathrm{mg} / \mathrm{L}$ each) during both the individual and combined treatments. Four enzymatic \\ transformation products (TPs) were identified during the individual treatments of DCF and CBZ by T. \\ versicolor. For TMP and SMX, no major TPs were observed under the experimental conditions used. The \\ toxicity of the solution before and after enzymatic treatment of each pharmaceutical was also assessed \\ and all treated effluent samples were verified to be non-toxic. \\ Disciplines \\ Engineering | Science and Technology Studies

\section{Publication Details} \\ Alharbi, S. K., Nghiem, L. D., Van De Merwe, J. P., Leusch, F. D.L., Asif, M. B., Hai, F. I. \& Price, W. E. (2019). \\ Degradation of diclofenac, trimethoprim, carbamazepine, and sulfamethoxazole by laccase from \\ Trametes versicolor: Transformation products and toxicity of treated effluent. Biocatalysis and \\ Biotransformation, 37 (6), 399-408.

\section{Authors} \\ Sultan Alharbi, Long D. Nghiem, Jason P. Van De Merwe, Frederic Leusch, Muhammad Bilal Asif, Faisal I. \\ Hai, and William E. Price
}




\section{Degradation of diclofenac, trimethoprim, carbamazepine, and}

\section{sulfamethoxazole by laccase from Trametes versicolor: transformation products and toxicity of treated effluent}

Sultan K. Alharbi ${ }^{\mathrm{a}, \mathrm{b}}$, Long D. Nghiem ${ }^{\mathrm{c}, \mathrm{d}}$, Jason P. van de Merwe ${ }^{\mathrm{e}}$, Frederic D. L. Leusch $^{\mathrm{e}}$, Muhammad B. Asif ${ }^{\mathrm{c}}$, Faisal I. Hai ${ }^{\mathrm{c}, *}$, and William E. Price ${ }^{\mathrm{a}}$

${ }^{a}$ Strategic Water Infrastructure Laboratory, School of Chemistry, University of Wollongong, NSW 2522, Australian (E-mail:skma437@uowmail.edu.au; wprice@uow.edu.au)

${ }^{b}$ Taibah University, Department of Chemistry, Madinah, Saudi Arabia

${ }^{c}$ Strategic Water Infrastructure Laboratory, School of Civil, Mining and Environmental Engineering, University of Wollongong, NSW 2522, Australia (E-mail: faisal@uow.edu.au; mba409@uowmail.edu.au)

${ }^{d}$ Centre for Technology in Water and Wastewater, School of Civil and Environmental Engineering, University of Technology Sydney, Sydney, NWS 2007, Australia (E-mail: DucLong.Nghiem@uts.edu.au)

${ }^{e}$ Australian Rivers Institute and School of Environment and Science, Griffith University, Qld, 4222, Australia (E-mail: j.vandemerwe@griffith.edu.au; f.leusch@griffith.edu.au)

*corresponding author: faisal@uow.edu.au; Tel.: +61-2-42213054 


\title{
Degradation of diclofenac, trimethoprim, carbamazepine, and sulfamethoxazole by laccase from Trametes versicolor: transformation products and toxicity of treated effluent
}

\begin{abstract}
The degradation of diclofenac (DCF), trimethoprim (TMP), carbamazepine (CBZ), and sulfamethoxazole (SMX) by laccase from Trametes versicolor was investigated. Experiments were conducted using the pharmaceuticals individually, or as a mixture at different initial concentrations ( 1.25 and $5 \mathrm{mg} / \mathrm{L}$ each). The initial enzymatic activity of all the treated samples was around $430-460 \mathrm{U}_{(\mathrm{DMP})} / \mathrm{L}$. The removal of the four selected pharmaceuticals tested individually was more effective than when tested in mixtures under the same conditions. For example, $5 \mathrm{mg}$ DCF/L was completely removed to below its detection limit $(1 \mu \mathrm{g} / \mathrm{L})$ within $8 \mathrm{~h}$ in the individual experiment vs after $24 \mathrm{~h}$ when dosed as a mixture with the other pharmaceuticals. A similar trend was visible with other three pharmaceuticals, with 95 vs $39 \%, 82$ vs $34 \%$ and 56 vs $49 \%$ removal after 48 $\mathrm{h}$ with $5 \mathrm{mg} / \mathrm{L}$ of TMP, CBZ, and SMX tested individually or as mixtures, respectively. In addition, at the lower initial concentration $(1.25 \mathrm{mg} / \mathrm{L}$ each $)$, the removal efficiency of TMP, CBZ, and SMX in mixtures was lower than that obtained at the higher initial concentrations ( $5 \mathrm{mg} / \mathrm{L}$ each) during both the individual and combined treatments. Four enzymatic transformation products (TPs) were identified during the individual treatments of DCF and CBZ by T. versicolor. For TMP and SMX, no major TPs were observed under the experimental conditions used. The toxicity of the solution before and after enzymatic treatment of each pharmaceutical was also assessed and all treated effluent samples were verified to be non-toxic.
\end{abstract}

Keywords: laccase; T. versicolor; pharmaceutical degradation; transformation product; toxicity assessment; wastewater treatment 


\section{Introduction}

Pharmaceutically active compounds (PhACs) such as diclofenac (DCF), trimethoprim (TMP), carbamazepine (CBZ), and sulfamethoxazole (SMX) have been regularly reported in wastewater effluent, ground water, surface water, and even drinking water (Kolpin et al. 2002; Morasch et al. 2010; Santos et al. 2010; Vulliet and Cren-Olivé 2011; Al Aukidy et al. 2012; Ratola et al. 2012; Padhye et al. 2014). Their occurrence has been attributed to their inefficient removal by wastewater treatment plants (WWTPs) (Kümmerer 2009; Miège et al. 2009; Luo et al. 2014). Although found in trace concentrations, the occurrence of PhACs in the environment has attracted much attention recently due to possible undesirable effects including development of bacterial resistance in the environment (Zhang et al. 2009), ecotoxicological impacts (Santos et al. 2010; Hai et al. 2018), and effects on endocrine systems of some aquatic organisms (Hoeger et al. 2005; Fent et al. 2006). Several advanced oxidation processes (e.g., ozonation, UV photolysis, and $\mathrm{UV} / \mathrm{H}_{2} \mathrm{O}_{2}$ ) have been explored to degrade these $\mathrm{PhACs}$. However a number of toxic transformation products (TPs) were reported in case of some advanced oxidation processes (Alharbi Sultan K. et al. 2017). Therefore, the removal of PhACs from water without production of toxic transformation products (TPs) during the treatment processes is important to improving water quality (Alharbi Sultan K. et al. 2017; Alharbi Sultan K. and Price 2017).

The degradation of PhACs using enzymes secreted by white rot fungi (WRF) has recently attracted interest as a method to obtain high removal efficiency and non-toxic effluents (Yang et al. 2013). WRF comprises a group of fungi which secret extracellular enzymes capable of degrading lignin, a complex natural compound protecting soft wood in trees. WRF secret lignin modifying enzymes, namely peroxidases e.g., lignin peroxidases (LiPs) and manganese-dependent peroxidases (MnPs) and laccase (Reddy 1995). Unlike peroxidases, laccase can catalyse pollutant degradation using oxygen dissolved in the reaction mixture. 
Laccase secreted by different fungi may have different redox potential (Piscitelli et al. 2011). The degradation of the four selected PhACs, namely, diclofenac (DCF), trimethoprim (TMP), carbamazepine (CBZ), and sulfamethoxazole (SMX) by laccase from $T$. versicolor has been previously investigated (Marco-Urrea et al. 2009; Tran et al. 2010; Margot J. et al. 2015; Ji et al. 2016). In addition, the use of redox-mediators as the electron accepter during enzymatic treatments has been found to improve biodegradation of some PhACs (Touahar et al. 2014; Margot J. et al. 2015). The effectiveness of DCF degradation by enzymatic treatments has been reported to vary. Laccase from T. versicolor, either crude or purified (i.e., commercially available), was found to achieve high DCF removal (> 70\%) (Tran et al. 2010; Margot Jonas et al. 2013; Nguyen Luong N. et al. 2014; Nguyen L. N. et al. 2014); and the use of a mediator was not found to affect DCF removal (Tran et al. 2010). However, laccase from other species were found to be less effective at PhACs degradation compared to T. versicolor (Lloret et al. 2010; Nguyen Luong N. et al. 2014; Nguyen L. N. et al. 2014; Nguyen et al. 2015). CBZ degradation by laccase from $T$. versicolor can vary significantly, depending on the initial concentration, enzymatic activity, and incubation time. For example, about $38 \%$ and only $5 \%$ of 0.01 and $4.72 \mathrm{mg} \mathrm{CBZ/L}$ were removed by laccase secreted by $T$. versicolor after 4 and 96 h of incubation, respectively (Tran et al. 2010; Ji et al. 2016).

In the limited studies on the degradation of the two antibiotics TMP and SMX by enzymatic treatment, TMP was reported to be poorly removed by laccase from $T$. versicolor (Touahar et al. 2014; Arca-Ramos et al. 2016). Contradictory reports on the ability of laccase from T. versicolor to degrade SMX can be noted in the literature. For example, $77 \%$ of $50 \mathrm{mg}$ SMX/L was removed by laccase from $T$. versicolor after one hour of incubation (Rahmani et al. 2015), whereas in a separate study, laccase from T. versicolor did not degrade SMX (at 20$25 \mathrm{mg} / \mathrm{L}$ ) within $72 \mathrm{~h}$ of incubation (Margot J. et al. 2015). However, the addition of a redoxmediator was able to achieve a complete elimination within $6 \mathrm{~h}$ of incubation. Therefore, it is 
important that the degradation of DCF, TMP, CBZ, and SMX by laccase from $T$. versicolor and also the identification of any potentially toxic TPs be more thoroughly investigated.

The main aim of this work was to critically assess the ability of laccase from $\mathrm{T}$. versicolor to degrade four selected PhACs, namely, diclofenac (DCF), trimethoprim (TMP), carbamazepine (CBZ), and sulfamethoxazole (SMX). This investigation included the degradation of each $\mathrm{PhAC}$ individually and in a mixture at different $\mathrm{PhAC}$ concentrations. A particular aim was to investigate the formation and fate of TPs during the enzymatic treatment, including confirmation of the molecular structure of the previously identified TPs using their $\mathrm{m} / \mathrm{z}$ ratio and mass fragmentation patterns. In addition, the relative toxicity of the treated mixtures with the original compounds was compared using a typical bacterial toxicity test. The combined investigation of the TPs and the toxicity of the test solution following enzymatic degradation address a significant gap in the literature.

\section{Materials and methods}

\subsection{PhACs and enzyme}

Four PhACs including diclofenac (DCF), trimethoprim (TMP) carbamazepine (CBZ), and sulfamethoxazole (SMX) were chosen for this study (Figure 1). Analytical grade PhACs were purchased from Sigma-Aldrich (Castle Hill, Australia). Commercial laccase powder from $T$. versicolor (activity $\geq 0.5 \mathrm{U} / \mathrm{mg}$ ) was also purchased from Sigma-Aldrich.<smiles>O=C(O)Cc1ccccc1Nc1c(Cl)cccc1Cl</smiles><smiles>COc1cc(Cc2cnc(N)nc2N)cc(OC)c1OC</smiles> 


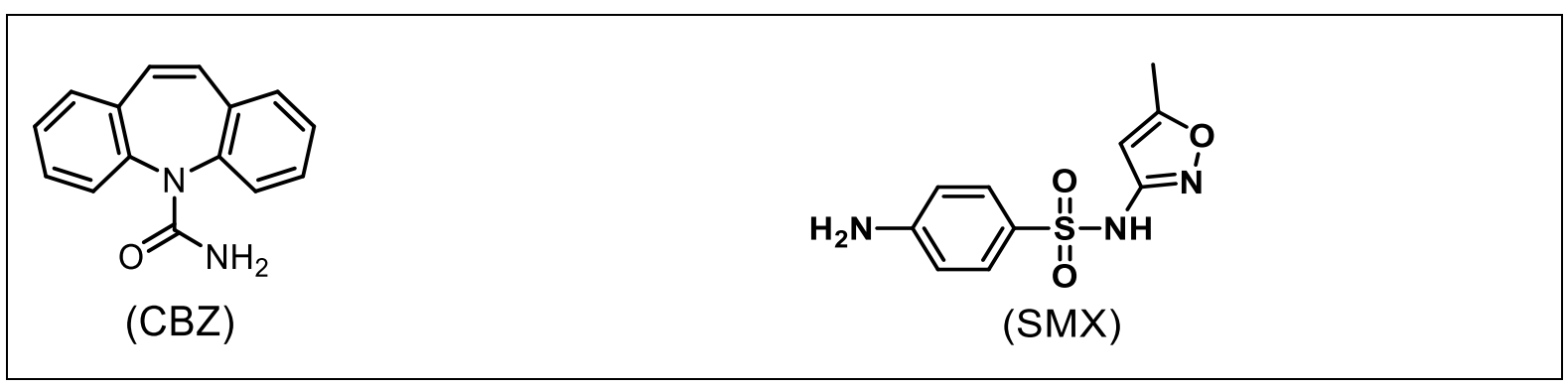

Figure 1. Chemical structures of the four PhACs selected. Diclofenac, trimethoprim, carbamazepine and sulfamethoxazole is denoted by DCF, TMP, CBZ and SMX, respectively.

\subsection{Enzymatic activity assay}

The activity of laccase was measured using a previous method by Paszczynski et al. (1991). Briefly, the oxidation of a substrate of laccase, namely, 2,6-dimethoxy phenol (DMP), at 10 $\mathrm{mM}$ was monitored for two min at room temperature in $100 \mathrm{mM}$ sodium citrate buffer $(\mathrm{pH} 4.5)$ solution. The change in absorbance at $468 \mathrm{~nm}$ due to degradation of DMP by laccase was monitored by a UV-visible spectrophotometer (DR3900, Hach, Colorado, USA). Laccase activity (expressed as $\mathrm{U}_{(\mathrm{DMP})} / \mathrm{L}$ ) was calculated using the molar extinction coefficient of 49.6 $\mathrm{mM}^{-1} \mathrm{~cm}^{-1}$.

\subsection{Enzymatic experimental procedure}

Stock solutions containing $5 \mathrm{~g} / \mathrm{L}$ of DCF, TMP, CBZ, and SMX were separately prepared in pure methanol, and then stored in amber bottles at $-18{ }^{\circ} \mathrm{C}$ prior to use. The degradation of 5 mg/L of DCF, TMP, CBZ, and SMX, by laccase from $T$. versicolor was first investigated for the PhACs individually. Following this, the degradation of each $\mathrm{PhAC}$ in a mixture with the others was investigated at different initial concentrations of the individual PhACs ( 5 and 1.25 $\mathrm{mg} / \mathrm{L}$ ). These PhACs have been detected in WWTPs at concentrations ranging from 0.001 to $0.1 \mathrm{mg} / \mathrm{L}$ (Luo et al. 2014). In this study, a relatively high concentration (i.e. 1.25 and $5 \mathrm{mg} / \mathrm{L}$ ) of each PhAC was selected in order to investigate the formation of transformation products. To generate transformation products at detectable level, it is a common practice to work with 
higher initial concentrations of contaminants than environmentally relevant (Hata et al. 2010; Jelic et al. 2012; Ji et al. 2016).

To investigate degradation efficiency, commercially available laccase from $T$. versicolor $(0.08 \mathrm{~g})$ was added to ultrapure Milli-Q water $(50 \mathrm{~mL})$ in aluminum foil covered $250 \mathrm{~mL}$ beakers to achieve an initial enzymatic activity of $c a .430-460 \mathrm{U}_{(\mathrm{DMP})} / \mathrm{L}$. When the targeted enzymatic activity was achieved, the selected $\mathrm{PhAC}$ concentrations were added to the enzyme solution in individual beakers. The beakers were incubated on a rotary shaker for $48 \mathrm{~h}$ at $80 \mathrm{rpm}$ and $25^{\circ} \mathrm{C}$. The $\mathrm{pH}$ of the reaction media was between 6.8 and 6.9 at the start of each experiment. The experiments were carried out in duplicate. Sub-samples were collected after $1,2,4,8,12,24$, and 48 hours of incubation by taking $0.5 \mathrm{~mL}$ and adding $0.5 \mathrm{~mL}$ of methanol to deactivate the laccase to arrest further degradation. The treated samples were then diluted to fit in the concentration-range of the calibration curve prior to analysis by LC-MS to calculate the removal efficiency over time.

For the detection of transformation products (TPs), $5 \mathrm{mg} / \mathrm{L}$ of DCF, TMP, CBZ, and SMX was added to the laccase solution (activity of 430-460 $\mathrm{U}_{(\mathrm{DMP})} / \mathrm{L}$ ) in individual beakers, and incubated as described above for $48 \mathrm{~h}$. At the conclusion of incubation, the treated effluent was collected and solid phase extraction (SPE) was used to extract the compounds prior to analysis by LC-MS (Alharbi S. K. et al. 2016). Pre-concentration with SPE cartridges increased the sensitivity of the LC-MS analysis to identify the TPs. The Sep-Pak SPE cartridges purchased from Waters (Rydalmere, NSW, Australia) possessed the following properties: C18, $6 \mathrm{cc} ; 55-105 \mu \mathrm{m}$ particle size; $500 \mathrm{mg}$ sorbent per cartridge. Before sample loading at a flow rate of $1-5 \mathrm{~mL} / \mathrm{min}$, the cartridges were pre-conditioned with (i) $7 \mathrm{~mL}$ dichloromethane and methanol mixture $(1: 1 \mathrm{v} / \mathrm{v})$, (ii) $7 \mathrm{~mL}$ of methanol, and (iii) $7 \mathrm{~mL}$ of Milli-Q water. The TPs extracted were then eluted from the cartridges using methanol $(3 \mathrm{~mL})$ at a flow rate of $1-5$ $\mathrm{mL} / \mathrm{min}$. This corresponded to a concentration factor of approximately 17 . 


\subsection{Analytical methods}

The analysis of the parent PhACs and any TPs were performed by a liquid chromatography electrospray ionisation - mass spectrometer (LC-ESI-MS) (Shimadzu single quadrupole LCMS 2020). A series of standard solutions for each parent compound was prepared for calibration purposes at $1,10,50,100$, and $200 \mu \mathrm{g} / \mathrm{L}$. The sample injection volume was $20 \mu \mathrm{L}$. The separation of the compounds was carried out by a Kinetex ${ }^{\circledR}$ Pentafluorophenyl (PFP) 100A column $(100 \mathrm{~mm} \times 3 \mathrm{~mm}, 2.6 \mu \mathrm{m})$ purchased from Phenomenex (Lane Cove, NSW, Australia). The column temperature was maintained at $31^{\circ} \mathrm{C}$. The mobile phase comprised of $0.1 \%$ formic acid in Milli-Q water (A) and acetonitrile (B). It was passed at a flow rate of 500 $\mu \mathrm{L} / \mathrm{min}$ in the following gradient elution (\%B): $0.01 \min (5 \%), 5 \min (10 \%), 20 \min (45 \%), 23$ $\min (90 \%), 28.1 \min (90 \%), 29 \min (10 \%), 33 \min (10 \%)$, and $35.01 \mathrm{~min}$ (controller stop). Both positive and negative ion modes were used to collect mass spectrometric data from $\mathrm{m} / \mathrm{z}$ 150 to 700 . In addition, selected scan mode was used to look for the particular $\mathrm{m} / \mathrm{z}$ of the previously reported TPs of DCF and CBZ after enzymatic treatment. All of the detector parameters were held constant during analysis. These include interface temperature $\left(350{ }^{\circ} \mathrm{C}\right)$, desolvation line (DL) temperature $\left(250^{\circ} \mathrm{C}\right)$, heat block temperature $\left(200{ }^{\circ} \mathrm{C}\right)$, dry gas flow $(3$ $\mathrm{L} / \mathrm{min})$, and nebulizing gas flow $(1.5 \mathrm{~L} / \mathrm{min})$.

\subsection{Toxicity assessment}

At the end of the incubation period, the treated and untreated solutions were collected and compounds were extracted using SPE cartridges (Section 2.3) and eluted in $2 \mathrm{~mL}$ of methanol. This corresponded to a SPE concentration factor of 25. Samples were stored in $2 \mathrm{~mL}$ amber vials and kept in a $-18{ }^{\circ} \mathrm{C}$ freezer prior to toxicity analysis.

The bacterial luminescence toxicity screen (BLT-Screen) developed by van de Merwe and Leusch (2015) was used to assess the toxicity of samples before and after the treatment. 
An aliquot of naturally bioluminescent bacteria, Photobacterium leiognathi, was incubated with a serial dilution of the sample extracts in a phosphate buffered saline solution. After 30 min, luminescence was measured on a Fluostar Omega plate reader (BMG Labtech, Germany). The luminescence inhibition was calculated relative to a negative control. The concentration of the sample required to inhibit bacterial luminescence by $20 \%$ was denoted IC20. It was computed for each sample by linear regression of the response between 0 and $40 \%$ inhibition. Results are presented as a relative toxicity unit (rTU), which is the reciprocal of the IC20.

\section{Results and discussion}

\subsection{Laccase-catalysed degradation of PhACs}

Laccase-catalysed degradation of a compound comprises the transition of an electron from the compound to laccase in presence of a co-factor (i.e., dissolved oxygen) (Yang et al. 2013; Asif et al. 2017; Asif et al. 2018). However, the extent of degradation by laccase is significantly affected by the molecular properties of the target compounds such as the presence of aromatic or heterocyclic rings, electron donating groups, coupled bonds, and/or readily oxidized substitutions (Tran et al. 2010). In addition, laccase can efficiently degrade phenolic PhACs, while the degradation of non-phenolic PhACs is only possible if the redox-potential of laccase is high enough or PhACs contain one or more electron donating groups (EDGs) (Lloret et al. 2010; Nguyen L. N. et al. 2014; Nguyen et al. 2015). Enzyme-catalysed reactions generally follow the Michaelis-Menten kinetic model, thus, it is also possible that degradation of $\mathrm{PhACs}$ by laccase may have attained an equilibrium after certain extent of removal (Berg, 2002). All the PhACs selected for this study were non-phenolic and their removal by laccase from $T$. versicolor during individual and combined treatments are discussed in the following sections. 


\subsubsection{Degradation of individual PhACs}

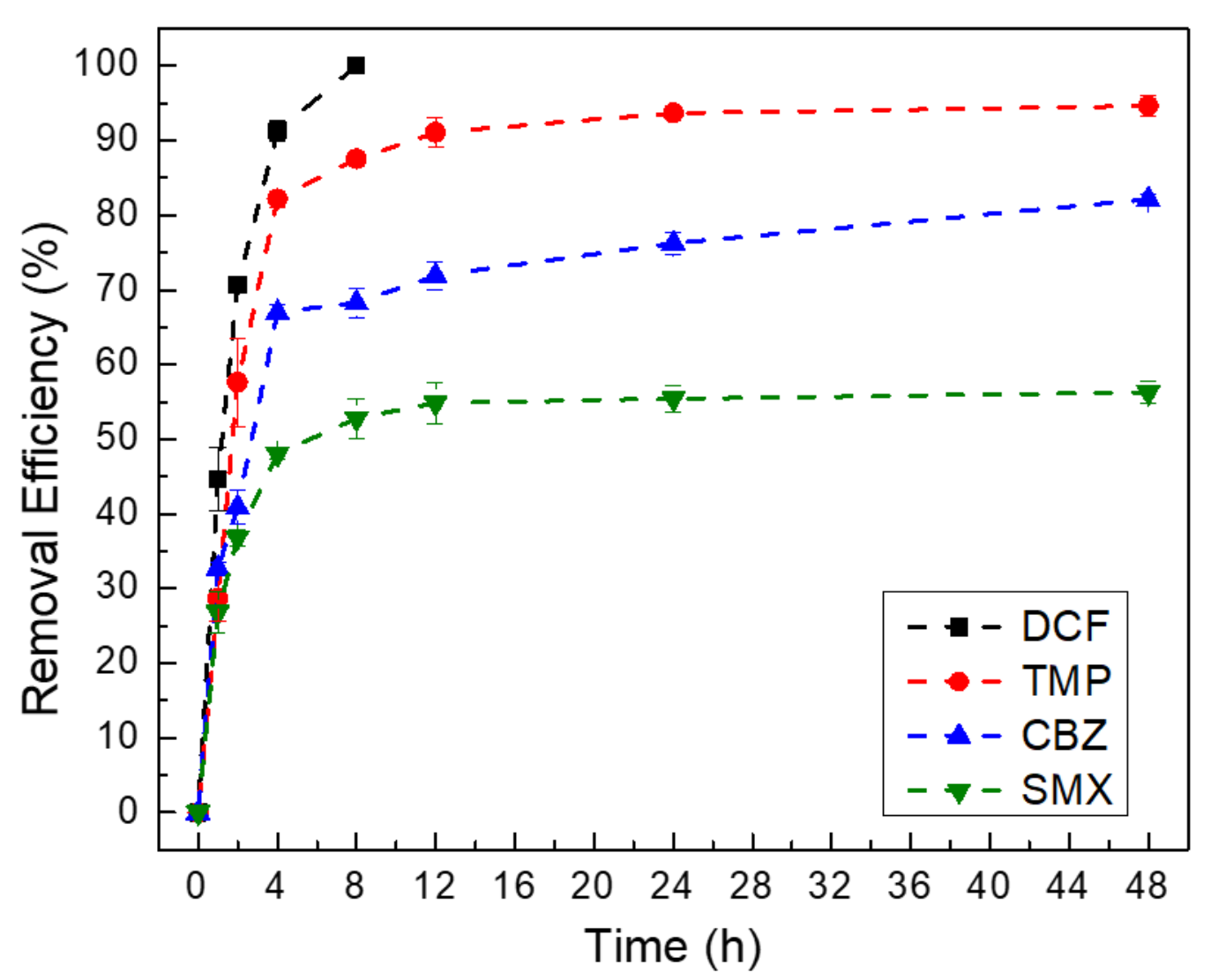

Figure 2. The individual degradation of $5 \mathrm{mg} / \mathrm{L}$ of each pharmaceutical (DCF, TMP, CBZ, and SMX) by laccase from T. versicolor.

The individual degradation of $5 \mathrm{mg} / \mathrm{L}$ of each $\mathrm{PhAC}$ by laccase from $T$. versicolor was evaluated over an incubation period of $48 \mathrm{~h}$. The individual degradation of the four selected PhACs by laccase appears to be influenced by their molecular properties. Experiments showed different reactivity of the four selected PhACs toward the applied enzymatic treatment (Figure 2). The initial degradation rates $\left(10^{-4} \mathrm{mgL}^{-1} \mathrm{~s}^{-1}\right)$ of the four $\mathrm{PhACs}$ were calculated during the first four hours of the incubation time. The maximal degradation rates of the four PhACs $\left(10^{-4}\right.$ $\mathrm{mgL}^{-1} \mathrm{~s}^{-1}$ ) were $5.0 \pm 0.2(\mathrm{DCF}), 3.9 \pm 0.3(\mathrm{TMP}), 2.8 \pm 0.1(\mathrm{CBZ})$, and $2.55 \pm 0.07$ (SMX).

Five mg DCF/L was degraded to below the experimental detection limit i.e., $1 \mu \mathrm{g} / \mathrm{L}$ within $8 \mathrm{~h}$ of incubation, in agreement with a previous study (Margot Jonas et al. 2013). The chemical structure of DCF includes an aromatic amine (an EDG) which may enhance its 
oxidation by laccase (Nguyen L. N. et al. 2014). For CBZ and TMP, fast degradation rates were initially observed ( $0-4 \mathrm{~h}$ of incubation time) during individual treatments of $5 \mathrm{mg} / \mathrm{L}$ of each $\mathrm{PhAC}$. Then, both PhACs were gradually degraded from 4 to $48 \mathrm{~h}$ of incubation time to achieve a total elimination of 95 and $82 \%$ for TMP and CBZ, respectively. This finding confirms the capacity of laccase from $T$. versicolor to efficiently degrade CBZ without using a redox mediator (Tran et al. 2010). This result somewhat contradicts previous literature findings on the capacity of laccase from $T$. versicolor to degrade CBZ. While previous studies have indicated that the presence of the electron withdrawing functional group 'amide' could generate an electron deficiency and consequently may reduce the susceptibility of CBZ to enzymatic oxidation (Nguyen L. N. et al. 2014), our results indicate that susceptibilities do exist, and provides new insight into CBZ degradation by laccase from $T$. versicolor.

For SMX, only $56 \%$ of the initial concentration was removed within $48 \mathrm{~h}$. It could be concluded that, DCF was highly susceptible to the oxidation by laccase from $T$. versicolor, whereas SMX was the most resistant $\mathrm{PhAC}$ during individual treatments under the applied conditions. 


\subsubsection{Degradation of PhACs in mixtures}
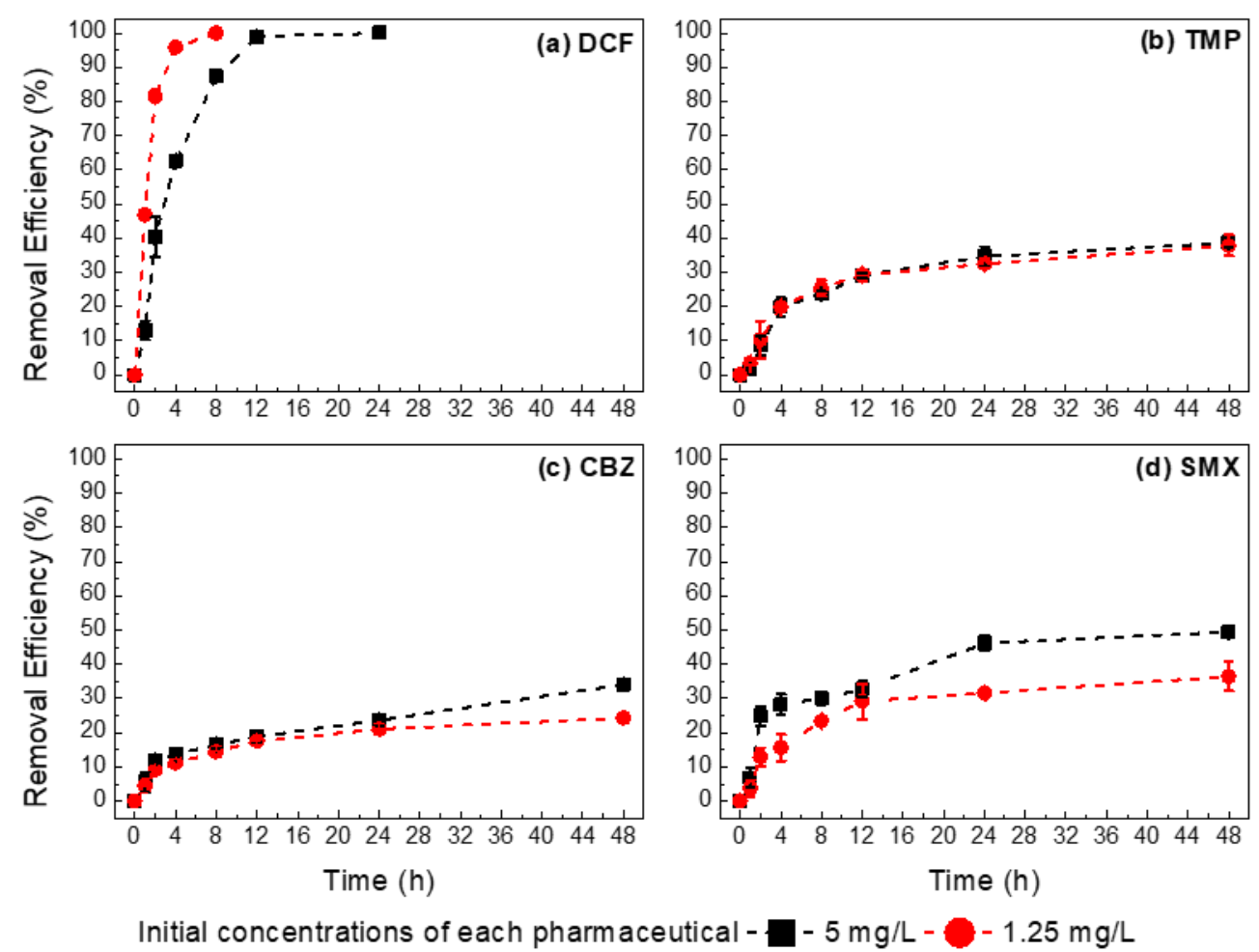

Figure 3. The effect of initial concentrations during degradation of (a) DCF, (b) TMP (c) CBZ, and (d) SMX in mixtures by laccase from T. versicolor.

The effect of different initial concentrations (i.e., 1.25 and $5 \mathrm{mg} / \mathrm{L}$ ) of the four selected $\mathrm{PhACs}$ in mixtures during treatments by laccase from T. versicolor was also investigated (Figure 3). The degradation of $5 \mathrm{mg} / \mathrm{L}$ of each $\mathrm{PhAC}$ in mixture showed initial rates $\left(10^{-4} \mathrm{mgL}^{-1} \mathrm{~s}^{-1}\right)$ of $2.23 \pm 0.05$ (DCF), $0.7 \pm 0.1$ (TMP), $0.46 \pm 0.05$ (CBZ), and $1.7 \pm 0.2$ (SMX). In addition, at initial $\mathrm{PhAC}$ concentrations of $1.25 \mathrm{mg} / \mathrm{L}$ each, the initial degradation rates $\left(10^{-4} \mathrm{mgL}^{-1} \mathrm{~s}^{-1}\right)$ in mixture were $1.41 \pm 0.03$ (DCF), $0.17 \pm 0.01$ (TMP), $0.15 \pm 0.02$ (CBZ), and $0.22 \pm 0.04$ (SMX). Independent of the initial $\mathrm{PhAC}$ concentrations, the results confirmed that the removal efficiency during the mixture treatments was not as effective as the individual treatments (Figures 2 and 3). The degradation of the four selected PhACs during combined treatments are likely affected by the molecular properties of each $\mathrm{PhAC}$, the total $\mathrm{PhAC}$ concentrations, and 
the competition between the four PhACs to be oxidised by laccase from T. versicolor.

DCF was highly degradable by laccase from $T$. versicolor during both the individual and combined treatments. This observation is consistent with that in a previous study which reported complete removal of DCF by laccase (Tran et al. 2010). For TMP, CBZ and SMX, better removal efficiency was achieved during treatment of the mixture at a higher initial concentration ( $5 \mathrm{mg} / \mathrm{L}$ each). Our results are consistent with those in a previous study where the efficiency of removal of several non-phenolic PhACs by laccase-enzymatic membrane reactor increased at a higher initial concentration (Nguyen et al. 2016).

\subsubsection{Effect of incubation time on degradation}

In this study, degradation of PhACs by laccase was evaluated over an incubation period of 48 $\mathrm{h}$, and samples were collected after regular intervals to investigate the significance of incubation time. It is clear from Figure 2 that individual $\mathrm{PhAC}$ degradation by laccase was fast initially, and the majority of degradation occurred within first $8 \mathrm{~h}$. For DCF, a complete removal was achieved within the first $8 \mathrm{~h}$ of incubation time when DCF was tested individually as well as in a mixture of PhACs at an initial concentration of $1.25 \mathrm{mg} / \mathrm{L}$ (Figure 2 and 3a). On the other hand, the degradation of CBZ, SMX and TMP in mixtures was observed to be rapid during the first $12 \mathrm{~h}$ of incubation time (Figure $3 \mathrm{~b}$-d). Then, their degradation by laccase slowed down from 13 to $24 \mathrm{~h}$ of incubation, and almost stopped for the remaining duration. This cease of degradation is probably due to the inactivation of laccase and/or kinetic limitations (Khlifi et al. 2010; Ashe et al. 2016). Therefore, incubation time is an important design criterion for determining the size of the bioreactor during the development of a treatment process. It should be carefully selected as overestimation could result in increasing the capital cost of the treatment process. 


\subsection{Formation of transformation products (TPS)}

The formation of TPs during the degradation of DCF, TMP, SMX, and CBZ by laccase from T. versicolor was investigated using LC-MS in both negative and positive scan mode (range, $\mathrm{m} / \mathrm{z} 150$ to 700 ). In addition, a selected ion mass mode was also used to detect the previously reported TPs during enzymatic treatments using their particular $\mathrm{m} / \mathrm{z}$. A total of four enzymatic TPs (two for DCF and two for CBZ) were detected at low abundance during the degradation by laccase. On the other hand, there were no TPs observed during degradation of TMP and SMX in the MS spectrum in either positive or negative scan mode.

For DCF, two isomer TPs with molecular ions of $\mathrm{m} / \mathrm{z} 310$ in a negative scan mode were detected (TP \#1 and \#2, see Figure 4). These TPs were eluted through the LC-MS column at 18.5 and $17.8 \mathrm{~min}$, respectively, before DCF elution at $21.5 \mathrm{~min}$. Based on their polarities, TP \#1 was formed by hydroxylation of the benzene ring that contains the two chlorine atoms, and had the highest abundance. The fragment ions obtained by MS of DCF TP \#1 confirmed the previously identified structure in the literature: it has a molecular weight of $311 \mathrm{~g} / \mathrm{mol}$, with molecular formula $\mathrm{C}_{14} \mathrm{H}_{11} \mathrm{Cl}_{2} \mathrm{NO}_{3}$. Collision induced dissociation of the $[\mathrm{M}-\mathrm{H}]-$ molecular ion of TP \#1 produced ions at $\mathrm{m} / \mathrm{z}$ of 266.1 and 230.1. Mass losses from the $[\mathrm{M}-\mathrm{H}+]$ ion were then calculated to be $44\left(\mathrm{CO}_{2}\right)$ and $80\left(\mathrm{CO}_{2}\right.$ and $\left.\mathrm{HCl}\right) \mathrm{g} / \mathrm{mol}$, respectively (Figure 4). These TPs were also identified during the oxidation of DCF by ozone, but at a higher abundance (Alharbi S. K. et al. 2016). They were formed mainly via hydroxylation at the para position of the amine group of the benzene rings, including 4'-OH diclofenac and 5-OH diclofenac (Marco-Urrea et al. 2010). Thus, their molecular structures differ by one extra oxygen atom with respect to DCF, without any changes in the benzene ring equivalence and double bond. One of them was produced at a relatively high abundance compared to the other. However, once the DCF was completely removed, both TPs were no longer detected, which indicates that they were also highly degradable by laccase. 
<smiles>O=C(O)Cc1ccccc1Nc1c(Cl)cccc1Cl</smiles>

(DCF)

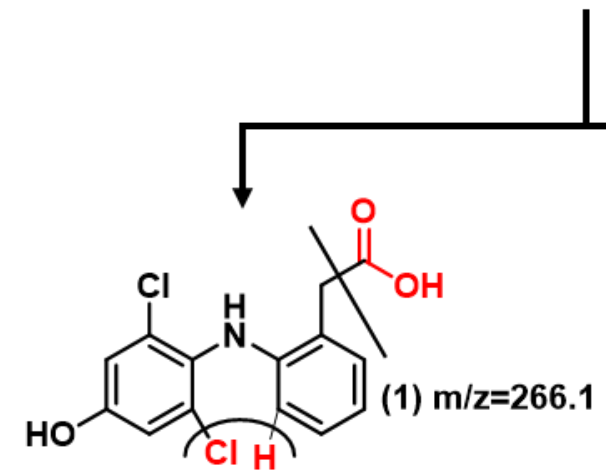

(2) $\mathrm{m} / \mathrm{z}=230.1$

(Transformation products \#1)
T. Versicolor<smiles>O=C(O)Cc1cc(O)ccc1Nc1c(Cl)cccc1Cl</smiles>

(Transformation products \#2)

Figure 4. The two isomers of DCF transformation products identified in this study. Fragmentation of transformation product \#1 is shown in red.

For CBZ, two TPs (TP \#3 and \#4, Figure 5) were detected at low abundance during degradation of CBZ by laccase. These TPs eluted at 14.6 and $15.4 \mathrm{~min}$ on the reverse-phase column and had molecular ions at m/z 253 and 196 in positive scan mode, respectively. Therefore, their molecular weights were determined to be 252 and $195 \mathrm{~g} / \mathrm{mol}$, with molecular formula of $\left(\mathrm{C}_{15} \mathrm{H}_{12} \mathrm{~N}_{2} \mathrm{O}_{2}\right)$ and $\left(\mathrm{C}_{13} \mathrm{H}_{9} \mathrm{NO}\right)$, respectively. The formation of both TPs during degradation of CBZ by laccase has been documented previously (Hata et al. 2010; Jelic et al. 2012; Ji et al. 2016). TP\#3 was identified as 11-epoxy-carbamazepine and consists of one extra oxygen atom with respect to molecular formula of CBZ. TP \#4 was identified as $(9(10 \mathrm{H})-$ acridone). Two other TPs with molecular weights of 253 and $180 \mathrm{~g} / \mathrm{mol}$, were reported during degradation of CBZ in another study (Jelic et al. 2012). However, none of these products was detected in the current study using both negative and positive selected ion mode, which indicated that they were not formed under the applied experimental conditions. TP \#3 has been previously identified during the degradation of CBZ by UV with $\mathrm{H}_{2} \mathrm{O}_{2}$, whereas TP \#4 was 
detected during both direct UV photolysis and also UV with only a small amount of $\mathrm{H}_{2} \mathrm{O}_{2}$ (Alharbi Sultan K. et al. 2017).

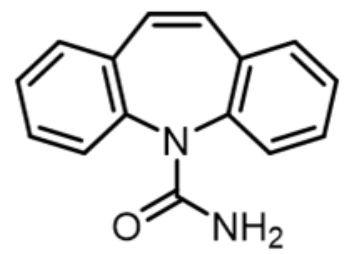

(CBZ)

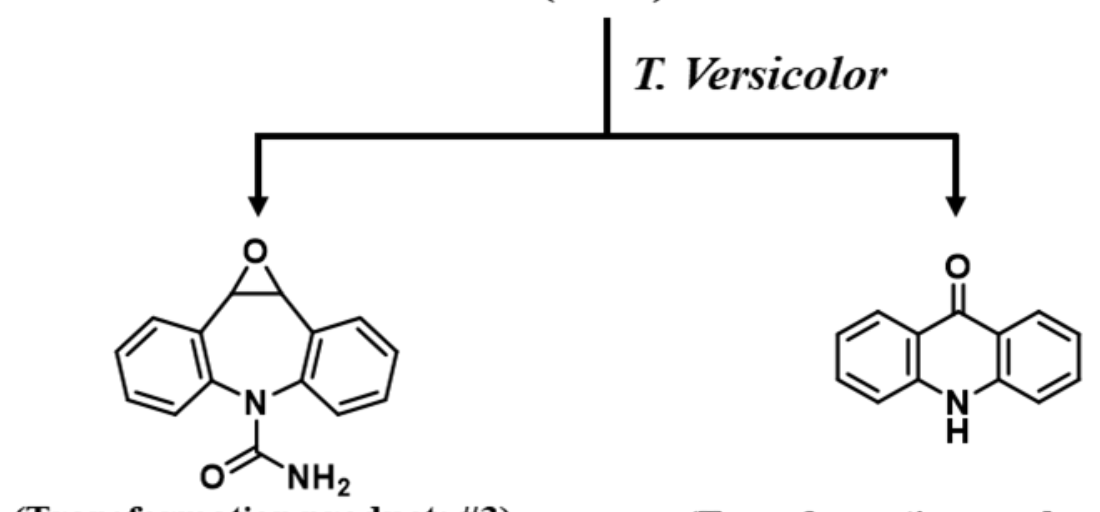

(Transformation products \#3)

(Transformation products \#4)

Figure 5. CBZ transformation products identified in the current study.

In conclusion, the laccase-mediated degradation of DCF, TMP, CBZ and SMX by laccase did not produce any major TPs under the experimental conditions used and LC-MS parameters employed. In addition, the detection of minor TPs was challenging due to the formation of many minor peaks in the LC chromatogram from the enzyme matrix. Most of these peaks were also observed after the treatment of each $\mathrm{PhAC}$ by laccase and had $\mathrm{m} / \mathrm{z}$ ranging from 150 to 700 in either negative or positive MS scan mode. Consequently, the detection of new minor PhAC TPs could not be readily achieved. For DCF and CBZ, the detection of minor TPs was achieved by using their previously reported $\mathrm{m} / \mathrm{z}$ in the literature. On the other hand, there was insufficient data in literature regarding the production of TPs during degradation of SMX and TMP by T. versicolor. For SMX, all the previous studies have treated SMX in the presence of other PhACs and/or mediators in order to improve SMX 
degradation (Shi et al. 2014; Margot J. et al. 2015). Therefore, the reported TPs were not fully transformed from SMX alone as there were other chemical compounds involved in the applied treatment. Additionally, in previous studies, the chemical structures of some identified SMX TPs consisted of the chemical structures of the mediators used. For TMP, there has not been any study to date on the formation of TPs by laccase treatment.

\subsection{Solution toxicity assessment}

Advanced oxidation processes, namely, UV photolysis, $\mathrm{UV} / \mathrm{H}_{2} \mathrm{O}_{2}$, and ozonation may transform the PhACs to a number of potentially toxic and/or resistant TPs (Alharbi S. K. et al. 2016; Alharbi Sultan K. et al. 2017). To check if this was similarly the case with enzymatic degradation, the toxicity of the four PhACs (DCF, TMP, CBZ, and SMX), their laccase-treated solution mixtures, and the pure laccase solution were evaluated. All the tested samples were found to be non-toxic in the BLT-Screen (all <2.5 rTU) at the PhAC concentrations tested. To the extent of our knowledge, this is the first report on the toxicity of TMP to bacteria before and after laccase treatment.

The data from this study indicate that the transformation of the selected PhACs by laccase from $T$. versicolor did not lead to formation of any significantly toxic TPs. A few previous studies have also reported that laccase-mediated degradation of DCF, CBZ, and SMX did not give rise to toxicity in the treated effluent (Marco-Urrea et al. 2010; Margot J. et al. 2015; Ji et al. 2016). However, by simultaneously monitoring TPs and effluent toxicity, in this study we are able to infer further that the TPs detected were at very low abundance (Section 3.2) which may not have the ability to affect the toxicity level.

It is interesting to compare the enzymatic degradation of the four selected $\mathrm{PhACs}$ with that by advanced oxidation processes (i.e., ozonation, $\mathrm{UV}$ photolysis, and $\mathrm{UV} / \mathrm{H}_{2} \mathrm{O}_{2}$ treatment) in terms of degradation of parent PhAC, formation of TPs, and toxicity assessment of treated 
solutions (Table 1). These experiments were carried out under the same experimental conditions (i.e., initial $\mathrm{PhAC}$ concentrations, individual $\mathrm{PhAC}$ treatment, and solution media) and using the same toxicity assessment assay (Alharbi S. K. et al. 2016; Alharbi Sultan K. et al. 2017). A complete elimination of DCF, TMP, CBZ, and SMX was achieved after the reaction with 2.3, 2.8, 1.6 and $4.6 \mathrm{mg} / \mathrm{L}$ of ozone, respectively (Alharbi S. K. et al. 2016). In addition, UV photolysis was able to completely remove DCF and SMX within a short time of UV exposure (8 min) (Alharbi Sultan K. et al. 2017). On the other hand, TMP and CBZ were reported to be resistant to direct UV photolysis, with approximately 71 and $25 \%$ removal after 90 and 60 min of UV exposure, respectively. However, the combination of UV with $0.12 \mathrm{mg}$ $\mathrm{H}_{2} \mathrm{O}_{2} / \mathrm{L}$ prior UV exposure significantly improved the removal of TMP and CBZ up to 97 and $99 \%$, respectively. Therefore, laccase from $T$. versicolor was able to achieve higher removals for TMP (95\%) and CBZ (82\%) than that achieved by direct UV photolysis under the same initial PhAC concentrations.

A wide range of resistant TPs was reported during degradation of the four PhAC by ozone, UV photolysis and $\mathrm{UV} / \mathrm{H}_{2} \mathrm{O}_{2}$ treatment. In addition, UV photolysis caused an increase in toxicity when applied to DCF, CBZ, and SMX (Alharbi et al. 2017). Similarly, ozonation of $\mathrm{CBZ}$ and DCF resulted in an increase in the toxicity of the treated solutions. This was ascribed to the formation of several major TPs that are more toxic than the original PhACs. Therefore, non-toxic effluent and more efficient degradation of TMP and CBZ by laccase than by direct UV photolysis indicate the relative benefit of enzymatic degradation. 
Table 1. Comparison of degradation of $5 \mathrm{mg} / \mathrm{L}$ of each $\mathrm{PhAC}$ by different oxidation processes.

\begin{tabular}{|c|c|c|c|c|c|c|}
\hline \multicolumn{2}{|c|}{ Treatment process } & $\mathrm{CBZ}$ & DCF & SMX & TMP & Reference \\
\hline \multirow{4}{*}{ Ozonation } & Dose (mg/L) & 1.6 & 2.3 & 4.5 & 2.8 & \multirow{4}{*}{$\begin{array}{c}\text { Alharbi S. } \\
\text { K. et al. } \\
\text { (2016) }\end{array}$} \\
\hline & Removal (\%) & 100 & 100 & 100 & 100 & \\
\hline & \# TPs & 7 & 11 & 13 & 15 & \\
\hline & Solution toxicity & Toxic & Toxic & $\begin{array}{l}\text { Non- } \\
\text { toxic }\end{array}$ & $\begin{array}{l}\text { Non- } \\
\text { toxic }\end{array}$ & \\
\hline \multirow{4}{*}{$\begin{array}{c}\text { UV } \\
\text { photolysis }\end{array}$} & $\begin{array}{l}\text { Exposure time } \\
\text { (min) }\end{array}$ & 60 & 8 & 8 & 90 & \multirow{9}{*}{$\begin{array}{l}\text { Alharbi } \\
\text { Sultan K. et } \\
\text { al. (2017) }\end{array}$} \\
\hline & Removal (\%) & 25 & 100 & 100 & 71 & \\
\hline & \# TPs & 13 & 15 & 12 & 5 & \\
\hline & Solution toxicity & Toxic & Toxic & $\begin{array}{l}\text { Non- } \\
\text { toxic }\end{array}$ & $\begin{array}{l}\text { Non- } \\
\text { toxic }\end{array}$ & \\
\hline \multirow{5}{*}{$\mathrm{UV} / \mathrm{H}_{2} \mathbf{O}_{2}$} & $\begin{array}{l}\text { Exposure time } \\
\text { (min) }\end{array}$ & 60 & 20 & NA & 90 & \\
\hline & $\mathrm{H}_{2} \mathrm{O}_{2}$ dose $(\mathrm{g} / \mathrm{L})$ & 0.12 & 0.12 & NA & 0.12 & \\
\hline & Removal (\%) & 99 & 100 & NA & 97 & \\
\hline & \# TPs & 12 & NA & NA & 8 & \\
\hline & Solution toxicity & $\begin{array}{l}\text { Non- } \\
\text { toxic }\end{array}$ & $\begin{array}{l}\text { Non- } \\
\text { toxic }\end{array}$ & NA & $\begin{array}{l}\text { Non- } \\
\text { toxic }\end{array}$ & \\
\hline \multirow{5}{*}{$\begin{array}{c}\text { Purified } \\
\text { laccase } \\
\text { from } T \text {. } \\
\text { versicolor }\end{array}$} & $\begin{array}{l}\text { Incubation time } \\
\text { (h) }\end{array}$ & 48 & 8 & 48 & 48 & \multirow{5}{*}{ This study } \\
\hline & $\begin{array}{l}\text { Enzymatic } \\
\text { activity (U/L) }\end{array}$ & $430-460$ & $430-460$ & $430-460$ & $430-460$ & \\
\hline & Removal (\%) & 82 & 100 & 56 & 95 & \\
\hline & \# TPs & 2 & 2 & 0 & 0 & \\
\hline & Solution toxicity & $\begin{array}{l}\text { Non- } \\
\text { toxic }\end{array}$ & $\begin{array}{l}\text { Non- } \\
\text { toxic }\end{array}$ & $\begin{array}{l}\text { Non- } \\
\text { toxic }\end{array}$ & $\begin{array}{l}\text { Non- } \\
\text { toxic }\end{array}$ & \\
\hline
\end{tabular}

NA: data not available; TPs: transformation products 


\section{Conclusion}

This study provides novel insights on the enzymatic degradation of four pharmaceutically active compounds (PhACs), namely diclofenac (DCF), trimethoprim (TMP), carbamazepine (CBZ), and sulfamethoxazole (SMX), which are commonly detected in wastewater and wastewater-impacted water bodies. The results of this study revealed that laccase can effectively degrade DCF (100\%), TMP (95\%) and CBZ (85\%), while SMX degradation was moderate (56\%). Notably, with the exception of DCF, degradation of the PhACs reduced significantly when the performance of laccase was assessed for the treatment of synthetic wastewater containing the mixture of PhACs. The rate of $\mathrm{PhAC}$ degradation was rapid when tested individually as compared to that in mixtures regardless of the initial PhAC concentrations. A total of four TPs were detected at low abundance during the degradation of DCF and CBZ by laccase from T. versicolor. For SMX and TMP, TPs were not detected under the applied treatment conditions and LC-MS parameters. All effluent samples treated by laccase from $T$. versicolor were non-toxic based on the bacterial luminescence toxicity assay. The advanced oxidation processes (AOPs) such as ozonation and $\mathrm{UV}-\mathrm{H}_{2} \mathrm{O}_{2}$ may often be more effective than laccase-based treatment systems. However, the treated effluent produced by AOPs can be more toxic than the parent PhACs. Enzyme based treatments therefore offer great potential as an alternative approach to treatment of pollutants in wastewater effluent. Future studies to verify these important findings in continuous-flow enzymatic bioreactors operated under non-sterile conditions is recommended.

Competing interest: The authors declare no competing interest.

Acknowledgement: PhD Scholarship support from Taibah University, Saudi Arabia, to Sultan Alharbi is gratefully acknowledged.

\section{Reference}


Al Aukidy M, Verlicchi P, Jelic A, Petrovic M, Barcelò D. 2012. Monitoring release of pharmaceutical compounds: Occurrence and environmental risk assessment of two WWTP effluents and their receiving bodies in the Po Valley, Italy [Article]. Science of the Total Environment. 438:15-25.

Alharbi SK, Kang J, Nghiem LD, van de Merwe JP, Leusch FDL, Price WE. 2017. Photolysis and UV/H2O2 of diclofenac, sulfamethoxazole, carbamazepine, and trimethoprim: Identification of their major degradation products by ESI-LC-MS and assessment of the toxicity of reaction mixtures. Process Safety and Environmental Protection. 112:222-234.

Alharbi SK, Price WE. 2017. Degradation and Fate of Pharmaceutically Active Contaminants by Advanced Oxidation Processes [journal article]. Current Pollution Reports. 3(4):268-280.

Alharbi SK, Price WE, Kang J, Fujioka T, Nghiem LD. 2016. Ozonation of carbamazepine, diclofenac, sulfamethoxazole and trimethoprim and formation of major oxidation products [Article]. Desalination and Water Treatment. 57(60):29340-29351. English.

Arca-Ramos A, Kumar VV, Eibes G, Moreira MT, Cabana H. 2016. Recyclable cross-linked laccase aggregates coupled to magnetic silica microbeads for elimination of pharmaceuticals from municipal wastewater [Article]. Environ Sci Pollut Res Int. 23(9):8929-8939.

Ashe B, Nguyen LN, Hai FI, Lee D-J, van de Merwe JP, Leusch FDL, Price WE, Nghiem LD. 2016. Impacts of redox-mediator type on trace organic contaminants degradation by laccase: Degradation efficiency, laccase stability and effluent toxicity. International Biodeterioration \& Biodegradation. 113:169-176.

Asif MB, Hai FI, Hou J, Price WE, Nghiem LD. 2017. Impact of wastewater derived dissolved interfering compounds on growth, enzymatic activity and trace organic contaminant removal of white rot fungi-a critical review. Journal of environmental management. 201:89-109.

Asif MB, Hai FI, Kang J, van de Merwe JP, Leusch FDL, Price WE, Nghiem LD. 2018. Biocatalytic degradation of pharmaceuticals, personal care products, industrial chemicals, steroid hormones and pesticides in a membrane distillation-enzymatic bioreactor. Bioresource Technol. 247(Supplement C):528-536. 
Berg J. 2002. Enzymes: Basic concepts and kinetics. In: Berg JM, Tymoczko JL, Stryer L, editors. Biochemistry. New York: W. H. Freeman; p. 189-225. (ISBN: 0716730510).

Fent K, Weston AA, Caminada D. 2006. Ecotoxicology of human pharmaceuticals. Aquatic Toxicology. 76(2):122-159.

Hai F, Yang S, Asif M, Sencadas V, Shawkat S, Sanderson-Smith M, Gorman J, Xu Z-Q, Yamamoto K. 2018. Carbamazepine as a Possible Anthropogenic Marker in Water: Occurrences, Toxicological Effects, Regulations and Removal by Wastewater Treatment Technologies. Water. 10(2):107.

Hata T, Shintate H, Kawai S, Okamura H, Nishida T. 2010. Elimination of carbamazepine by repeated treatment with laccase in the presence of 1-hydroxybenzotriazole. Journal of Hazardous Materials. 181(1-3):1175-1178.

Hoeger B, Köllner B, Dietrich DR, Hitzfeld B. 2005. Water-borne diclofenac affects kidney and gill integrity and selected immune parameters in brown trout (Salmo trutta f. fario) [Article]. Aquatic Toxicology. 75(1):53-64.

Jelic A, Cruz-Morató C, Marco-Urrea E, Sarrà M, Perez S, Vicent T, Petrović M, Barcelo D. 2012. Degradation of carbamazepine by Trametes versicolor in an air pulsed fluidized bed bioreactor and identification of intermediates. Water Research. 46(4):955-964.

Ji C, Hou JW, Wang K, Zhang YT, Chen V. 2016. Biocatalytic degradation of carbamazepine with immobilized laccase-mediator membrane hybrid reactor. J Membrane Sci. 502:11-20. English.

Khlifi R, Belbahri L, Woodward S, Ellouz M, Dhouib A, Sayadi S, Mechichi T. 2010. Decolourization and detoxification of textile industry wastewater by the laccasemediator system. Journal of Hazardous Materials. 175(1):802-808.

Kolpin DW, Furlong ET, Meyer MT, Thurman EM, Zaugg SD, Barber LB, Buxton HT. 2002. Pharmaceuticals, hormones, and other organic wastewater contaminants in U.S. streams, 1999-2000: A national reconnaissance. Environmental Science and Technology. 36(6):1202-1211.

Kümmerer K. 2009. The presence of pharmaceuticals in the environment due to human use present knowledge and future challenges [Review]. Journal of Environmental Management. 90(8):2354-2366. 
Lloret L, Eibes G, LÃº-Chau TA, Moreira MT, Feijoo G, Lema JM. 2010. Laccase-catalyzed degradation of anti-inflammatories and estrogens. Biochemical Engineering Journal. 51(3):124-131.

Luo Y, Guo W, Ngo HH, Nghiem LD, Hai FI, Zhang J, Liang S, Wang XC. 2014. A review on the occurrence of micropollutants in the aquatic environment and their fate and removal during wastewater treatment. Science of The Total Environment. 473474:619-641.

Marco-Urrea E, Pérez-Trujillo M, Cruz-Morató C, Caminal G, Vicent T. 2010. Degradation of the drug sodium diclofenac by Trametes versicolor pellets and identification of some intermediates by NMR. Journal of Hazardous Materials. 176(1-3):836-842.

Marco-Urrea E, Pérez-Trujillo M, Vicent T, Caminal G. 2009. Ability of white-rot fungi to remove selected pharmaceuticals and identification of degradation products of ibuprofen by Trametes versicolor. Chemosphere. 74(6):765-772.

Margot J, Copin PJ, von Gunten U, Barry DA, Holliger C. 2015. Sulfamethoxazole and isoproturon degradation and detoxification by a laccase-mediator system: Influence of treatment conditions and mechanistic aspects [Article]. Biochemical Engineering Journal. 103:47-59.

Margot J, Maillard J, Rossi L, Barry DA, Holliger C. 2013. Influence of treatment conditions on the oxidation of micropollutants by Trametes versicolor laccase. New Biotechnology. 30(6):803-813.

Miège C, Choubert JM, Ribeiro L, Eusèbe M, Coquery M. 2009. Fate of pharmaceuticals and personal care products in wastewater treatment plants - Conception of a database and first results [Article]. Environmental Pollution. 157(5):1721-1726.

Morasch B, Bonvin F, Reiser H, Grandjean D, De Alencastro LF, Perazzolo C, Chèvre N, Kohn T. 2010. Occurrence and fate of micropollutants in the Vidy Bay of Lake Geneva, Switzerland. Part II: Micropollutant removal between wastewater and raw drinking water [Article]. Environmental Toxicology and Chemistry. 29(8):1658-1668.

Nguyen LN, Hai FI, Price WE, Kang JG, Leusch FDL, Roddick F, van de Merwe JP, Magram SF, Nghiem LD. 2015. Degradation of a broad spectrum of trace organic contaminants by an enzymatic membrane reactor: Complementary role of membrane 
retention and enzymatic degradation. International Biodeterioration \& Biodegradation. 99:115-122. English.

Nguyen LN, Hai FI, Price WE, Leusch FDL, Roddick F, Ngo HH, Guo W, Magram SF, Nghiem LD. 2014. The effects of mediator and granular activated carbon addition on degradation of trace organic contaminants by an enzymatic membrane reactor. Bioresource Technol. 167:169-177.

Nguyen LN, Hai FI, Yang SF, Kang JG, Leusch FDL, Roddick F, Price WE, Nghiem LD. 2014. Removal of pharmaceuticals, steroid hormones, phytoestrogens, UV-filters, industrial chemicals and pesticides by Trametes versicolor: Role of biosorption and biodegradation. International Biodeterioration \& Biodegradation. 88:169-175. English.

Nguyen LN, van de Merwe JP, Hai FI, Leusch FD, Kang J, Price WE, Roddick F, Magram SF, Nghiem LD. 2016. Laccase-syringaldehyde-mediated degradation of trace organic contaminants in an enzymatic membrane reactor: Removal efficiency and effluent toxicity [Article]. Bioresour Technol. 200:477-484.

Padhye LP, Yao H, Kung'u FT, Huang CH. 2014. Year-long evaluation on the occurrence and fate of pharmaceuticals, personal care products, andendocrine disrupting chemicals in an urban drinking water treatment plant [Article]. Water Research. 51:266-276.

Paszczynski A, Pasti-Grigsby MB, Goszczynski S, Crawford DL, Crawford RL. 1991. A new approach to improve degradation of recalcitrant azo dyes by Streptomyces spp. and Phanerochaete chrysosporium. Enzyme Microb Technol. 13:378-84.

Piscitelli A, Del Vecchio C, Faraco V, Giardina P, Macellaro G, Miele A, Pezzella C, Sannia G. 2011. Fungal laccases: Versatile tools for lignocellulose transformation [doi: 10.1016/j.crvi.2011.06.007]. Comptes Rendus Biologies. 334(11):789-794.

Rahmani K, Faramarzi MA, Mahvi AH, Gholami M, Esrafili A, Forootanfar H, Farzadkia M. 2015. Elimination and detoxification of sulfathiazole and sulfamethoxazole assisted by laccase immobilized on porous silica beads. International Biodeterioration \& Biodegradation. 97:107-114. 
Ratola N, Cincinelli A, Alves A, Katsoyiannis A. 2012. Occurrence of organic microcontaminants in the wastewater treatment process. A mini review [Article]. Journal of Hazardous Materials. 239-240:1-18.

Reddy CA. 1995. The potential for white-rot fungi in the treatment of pollutants [Article]. Current Opinion in Biotechnology. 6(3):320-328.

Santos LHMLM, Araújo AN, Fachini A, Pena A, Delerue-Matos C, Montenegro MCBSM. 2010. Ecotoxicological aspects related to the presence of pharmaceuticals in the aquatic environment. Journal of Hazardous Materials. 175(1-3):45-95.

Shi L, Ma F, Han Y, Zhang X, Yu H. 2014. Removal of sulfonamide antibiotics by oriented immobilized laccase on $\mathrm{Fe} 3 \mathrm{O} 4$ nanoparticles with natural mediators. J Hazard Mater. 279:203-211.

Touahar IE, Haroune I, Ba S, Bellenger JP, Cabana H. 2014. Characterization of combined cross-linked enzyme aggregates from laccase, versatile peroxidase and glucose oxidase, and their utilization for the elimination of pharmaceuticals. Science of the Total Environment. 481:90-99. English.

Tran HN, Urase T, Kusakabe O. 2010. Biodegradation Characteristics of Pharmaceutical Substances by Whole Fungal Culture Trametes versicolor and its Laccase. Journal of Water and Environment Technology. 8(2):125-140.

van de Merwe JP, Leusch FDL. 2015. A sensitive and high throughput bacterial luminescence assay for assessing aquatic toxicity - the BLT-Screen [10.1039/C5EM00012B]. Environmental Science: Processes \& Impacts. 17(5):947955.

Vulliet E, Cren-Olivé C. 2011. Screening of pharmaceuticals and hormones at the regional scale, in surface and groundwaters intended to human consumption. Environmental Pollution. 159(10):2929-2934.

Yang S, Hai FI, Nghiem LD, Price WE, Roddick F, Moreira MT, Magram SF. 2013. Understanding the factors controlling the removal of trace organic contaminants by white-rot fungi and their lignin modifying enzymes: A critical review [Article]. Bioresource Technol. 141:97-108.

Zhang XX, Zhang T, Fang HHP. 2009. Antibiotic resistance genes in water environment [Short Survey]. Applied Microbiology and Biotechnology. 82(3):397-414. 